\title{
Experimental Models for Testing Attraction and Preferential Behaviour of Steinernema glaseri to Several Insects
}

\author{
Anwar L. Bilgrami ${ }^{1,2}$, Eizo Kondo ${ }^{1}$ and Toyoshi YoshigA ${ }^{1}$
}

\begin{abstract}
Two experimental models, one for testing the attraction behaviour (Petri-dish scoring system) and the other for analyzing preferential behaviour (preference test chambers) of infective juveniles of Steinernema glaseri are described and proposed. Petri-dish scoring system was based on the probability of nematode distribution in the presence and absence of the insects. It was given weightage, depending upon the number of nematodes reaching to the insects. The weighted responses were given ranks and scores to make quantitative analysis of the attraction behaviour of nematodes. The preference test chambers were designed to test preferential behaviour of the nematodes for the larvae of four insect species: Galleria mellonella, Spodoptera litura, Blattella germanica and Locust migratoria. The attraction rates of S. glaseri increased with the time and reached to maximum (67.6\%) $6 \mathrm{hr}$ after inoculation of the nematodes. S. glaseri responded to homogenate of $G$. mellonella larvae in a dose dependent manner. Maximum values for the absolute and relative preferential indices showed that the nematodes preferred G. mellonella most among the four insects examined. Jpn. J. Nematol. 30 (1/2): 35-46 (2000).

Key words: attractants, behaviour, Blattella germanica, Galleria mellonella, Locust migratoria, Spodoptera litura.
\end{abstract}

The attraction behaviour of nematodes is a fascinated but most difficult and challenged aspect of study. It is all the more so, since nematodes are tiny and microscopic organisms living under physio-chemical influences of the soil environment. No doubt, experimental models using medium similar to their natural habitat has an advantage as it allows nematodes to exhibit normal behaviour but accomplishment of such a technique is rather difficult, if not impossible, due to the microhabitat and microscopic size of the nematodes. Good results have been obtained using soil and sand columns or by pot experiments $(5,8)$, but many important behavioural milestones may go unrecorded that would otherwise provide significant information about sensing behaviour of the nematodes. The other option to study behaviour is the two-dimensional bioassay using agar or agarose as the medium with conditions maintained as close to the natural habitat $(3,4)$ as possible. For such observations, a hypothesis explaining behaviour of nematodes under natural conditions may be erected depending upon the factual data. To be able to define chemical cues and stimuli involved in the migration of nematodes it is required to develop simpler and uniform systems based on quantitative and numerical estimations of nematode responses to chemical cues by excluding most of the possible external factors that may cause coincidental redistribution of nematodes. Numerous bioassays have been designed to suit particular nematodes viz., predatory

${ }^{1}$ Department of Applied Biological Sciences, Faculty of Agriculture, Saga University, Saga 840-8502, Japan.

2 JSPS Visiting Fellow: to whom correspondence may be addressed at email: bilgrami1956@ hotmail.com 
nematodes (3), plant parasitic nematodes (2, 4), entomopathogenic nematodes (7), and freeliving nematodes (10) but neither was based on the system which could assess nematode's response quantitatively except the two studies $(2,9)$. Therefore, a system is needed where the nematode responses to chemical cues may be assessed quantitatively by giving weighted ranks and scores to their responses depending upon patterns of their distribution.

Keeping in view the lack of standard and uniform ordinal system to test the attraction and preferential behaviour of Steinernema glaseri to insect emitted attractants, two experimental models were designed and proposed in this paper.

\section{MATERIALS AND METHODS}

Infective 3rd stage juveniles (IJs) of S. glaseri (Product name: Biotopia ${ }^{\circledR}$ ) were obtained from SDS Biotech K. K., Tsukuba Technology Center, Ibaraki, Japan for testing their attraction and preferential behaviour using the proposed experimental models. Nematodes were extracted into phosphate buffered saline (20 mM potassium phosphate and $150 \mathrm{mM}$ sodium chloride, $\mathrm{pH} 7.2$ ) and surface-sterilized with $0.01 \%$ streptomycin solution. They were left in fresh saline for one day at $28 \pm 1^{\circ} \mathrm{C}$ before being tested. The last instar of the greater wax moth, Galleria mellonella, and the 3rd instars of the common cutworm, Spodoptera litura, the German cockroach, Blattella germanica, and the grasshopper, Locust migratoria were obtained from the cultures maintained in the laboratory. For all experiments surface-washed larvae of the insects were used. All experiments were carried out at $28 \pm 1^{\circ} \mathrm{C}$.

Petri-dish scoring system: The test arena for the proposed Petri-dish scoring system was an $8.5 \mathrm{~cm}$ diam. Petri-dish (Fig. 1). The Petri-dish was divided into three zones viz., the inner, middle, and outer by drawing in two concentric circles of 1.5 and $3.5 \mathrm{~cm}$ in diam. on the bottom surface of the Petri-dish. The inner circle was designated as the incubation, the middle as the transitional, and the outer as the free zone. A $2 \mathrm{~mm}$ thick layer of 1\% water agar was made in

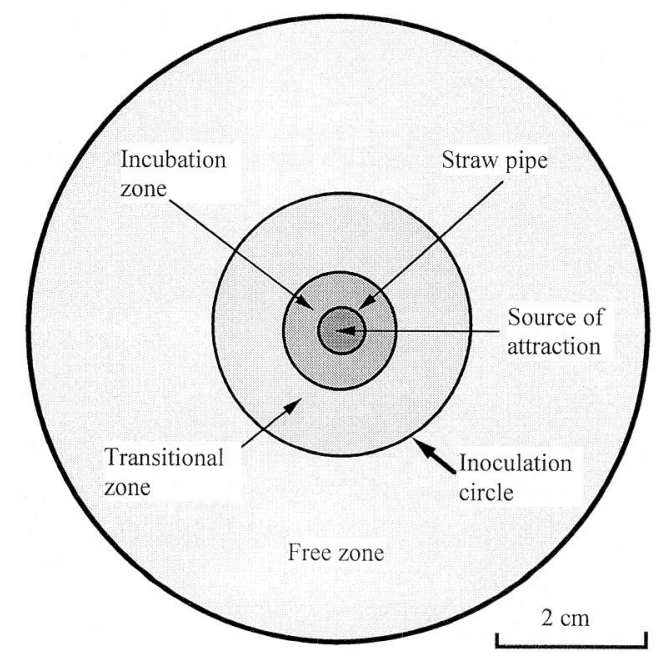

Fig. 1. Petri-dish scoring system designed to test attraction response of Steinernema glaseri to insect emitted kairomones. 
the Petri-dish and allowed to cool. A plastic straw pipe measuring $1.5 \mathrm{~cm}$ in length and $10 \mathrm{~mm}$ and $8 \mathrm{~mm}$ in the inner upper and bottom diam., respectively was taken. One of its end was glued with a piece of 200 mesh nylon sieve. Larvae of the insect to be tested were released into this pipe. To prevent the escape of the larvae, the open end of the pipe was sealed with a piece of cello-tape. The straw pipe containing insect larvae was then placed vertically in the middle of the incubation zone so as the end that was sealed with the nylon sieve remained inside the agar. The whole set was then left for $12 \mathrm{hr}$ to allow insect attractants to diffuse and develop minimum perceptible attraction gradient in the medium. After incubation $10 \mathrm{IJs}$ of $S$. glaseri were released at various points of the periphery of the transitional zone that is referred here as the inoculation circle (Fig. 1). The distribution of nematodes was examined in the three zones of the test arena 1,2, 3, 4, 5, and $6 \mathrm{hr}$ after inoculation. The nematode's distribution in the three zones corresponds to 66 combinations (Table 1). Each of the 66 distribution patterns were given a rank depending upon the number of nematodes reaching to the incubation zone (Table 1). The area of each zone was calculated and weighted factors (Wf) were obtained by dividing the area of the free zone with each of the three zones with the help of the following.

Weighted factor $(\mathrm{Wf})=\frac{\text { Area of the free zone }}{\text { Area of a zone }}$

The area and weighted factors for each zone are given in Table 2.

Scores were obtained by summing up the products of number of nematodes in each zone with their corresponding weighted factors. The scores for different distribution patterns of nematodes thus obtained were used to calculate attraction response of nematodes towards the insect emitted attractants as follows.

Attraction response $(\%)=\frac{\text { Observed score }}{\text { Maximum tabulated score }} \times 100$

The maximum tabulated score is 321 i.e., when all the nematodes were present in the incubation zone (Table 1$)$. The scores were obtained as follows.

Score $=\left(\mathrm{N}_{\mathrm{IZ}} \times \mathrm{Wf}_{\mathrm{IZ}}\right)+\left(\mathrm{N}_{\mathrm{TZ}} \times \mathrm{Wf}_{\mathrm{TZ}}\right)\left(\mathrm{N}_{\mathrm{FZ}} \times \mathrm{Wf}_{\mathrm{FZ}}\right)$

Where: $\mathrm{N}_{\mathrm{IZ}}, \mathrm{N}_{\mathrm{TZ}}, \mathrm{N}_{\mathrm{FZ}}$ are the number of nematodes present in the incubation, transitional and free zones, respectively and $\mathrm{Wf}_{\mathrm{IZ}}, \mathrm{Wf}_{\mathrm{TZ}}, \mathrm{Wf}_{\mathrm{FZ}}$ are the weighted factors for the incubation, transitional and free zones, respectively.

The presence of all nematodes in the incubation zone show high ranking i.e., 66 and thus show $100 \%$ response to insect attractants (Table 1). Therefore, the score of " 321 " was considered for obtaining relative values of the attraction responses of nematodes in the presence or absence of insects. The experiments were replicated 20 times. The mean of all replicates was taken and referred as the mean attraction response. The values of mean attraction response were used to represent the responses of nematodes to insect attractants. The experiments were conducted at $28 \pm 1^{\circ} \mathrm{C}$. The control experiments were run without insects.

Responses of $\mathrm{S}$. glaseri towards attractants emitted by the insects: The responses of S. glaseri towards insect emitting attractants were tested using Petri-dish scoring system as described above. All conditions remained same. Two last instar larvae of $G$. mellonella were incubated in the incubation zone. The distribution of nematodes in each zone was recorded after 1, 2, 3, 4, 5, and $6 \mathrm{hr}$ and their corresponding scores, ranks and attraction responses were obtained from Table 1 . 
Table 1. Sixty six possible combinations of nematode distribution in the three zones of the Petri-dish scoring system with their corresponding ranks, scores and attraction responses.

\begin{tabular}{|c|c|c|c|c|c|c|}
\hline SN. & $\begin{array}{c}\text { Incubation } \\
\text { zone }\end{array}$ & $\begin{array}{c}\text { Transitional } \\
\text { zone }\end{array}$ & $\begin{array}{l}\text { Free } \\
\text { zone }\end{array}$ & Ranks & Score & $\begin{array}{c}\text { Attraction } \\
\text { response (\%) }\end{array}$ \\
\hline 1. & 10 & 0 & 0 & 66 & 321 & 100 \\
\hline 2. & 9 & 1 & 0 & 65 & 296 & 92 \\
\hline 3 & 9 & 0 & 1 & 64 & 291 & 90 \\
\hline 4. & 8 & 2 & 0 & 63 & 269 & 84 \\
\hline 5. & 8 & 1 & 1 & 62 & 265 & 82 \\
\hline 6. & 8 & 0 & 2 & 61 & 260 & 81 \\
\hline 7. & 7 & 3 & 0 & 60 & 243 & 75 \\
\hline 8. & 7 & 2 & 1 & 59 & 238 & 74 \\
\hline 9. & 7 & 1 & 2 & 58 & 232 & 72 \\
\hline 10 & 7 & 0 & 3 & 57 & 228 & 71 \\
\hline 11. & 6 & 4 & 0 & 56 & 217 & 67 \\
\hline 12. & 6 & 3 & 1 & 55 & 212 & 66 \\
\hline 13. & 6 & 2 & 2 & 54 & 207 & 64 \\
\hline 14 & 6 & 1 & 3 & 53 & 202 & 62 \\
\hline 15 & 6 & 0 & 4 & 52 & 197 & 61 \\
\hline 16. & 5 & 5 & 0 & 51 & 191 & 59 \\
\hline 17. & 5 & 4 & 1 & 50 & 186 & 58 \\
\hline 18. & 5 & 3 & 2 & 49 & 181 & 56 \\
\hline 19. & 5 & 2 & 3 & 48 & 176 & 55 \\
\hline 20. & 5 & 1 & 4 & 47 & 171 & 53 \\
\hline 21. & 5 & 0 & 5 & 46 & 166 & 52 \\
\hline 22 & 4 & 6 & 0 & 45 & 164 & 51 \\
\hline 23. & 4 & 5 & 1 & 44 & 159 & 49 \\
\hline 24. & 4 & 4 & 2 & 43 & 154 & 48 \\
\hline 25. & 4 & 3 & 3 & 42 & 150 & 47 \\
\hline 26. & 4 & 2 & 4 & 41 & 145 & 45 \\
\hline 27. & 4 & 1 & 5 & 40 & 139 & 43 \\
\hline 28. & 4 & 0 & 6 & 39 & 135 & 42 \\
\hline 29. & 3 & 7 & 0 & 38 & 138 & 43 \\
\hline 30 . & 3 & 6 & 1 & 37 & 133 & 41 \\
\hline 31. & 3 & 5 & 2 & 36 & 128 & 40 \\
\hline 32 . & 3 & 4 & 3 & 35 & 123 & 38 \\
\hline 33. & 3 & 3 & 4 & 34 & 118 & 37 \\
\hline 34. & 3 & 2 & 5 & 33 & 113 & 35 \\
\hline 35. & 3 & 1 & 6 & 32 & 109 & 34 \\
\hline 36. & 3 & 0 & 7 & 31 & 104 & 32 \\
\hline 37. & 2 & 8 & 0 & 30 & 112 & 35 \\
\hline 38. & 2 & 7 & 1 & 29 & 106 & 33 \\
\hline 39. & 2 & 6 & 2 & 28 & 102 & 32 \\
\hline 40. & 2 & 5 & 3 & 27 & 97 & 30 \\
\hline 41. & 2 & 4 & 4 & 26 & 92 & 29 \\
\hline 42 & 2 & 3 & 5 & 25 & 87 & 27 \\
\hline 43 & 2 & 2 & 6 & 24 & 82 & 25 \\
\hline 44. & 2 & 1 & 7 & 23 & 77 & 24 \\
\hline 45 & 2 & 0 & 8 & 22 & 72 & 22 \\
\hline 46. & 1 & 9 & 0 & 21 & 85 & 26 \\
\hline 47. & 1 & 8 & 1 & 20 & 80 & 25 \\
\hline 48. & 1 & 7 & 2 & 19 & 76 & 24 \\
\hline 49. & 1 & 6 & 3 & 18 & 71 & 22 \\
\hline 50. & 1 & 5 & 4 & 17 & 66 & 20 \\
\hline 51. & 1 & 4 & 5 & 16 & 61 & 19 \\
\hline 52. & 1 & 3 & 6 & 15 & 56 & 17 \\
\hline 53. & 1 & 2 & 7 & 14 & 51 & 16 \\
\hline 54. & 1 & 1 & 8 & 13 & 46 & 14 \\
\hline 55. & 1 & 0 & 9 & 12 & 41 & 13 \\
\hline 56. & 0 & 10 & 0 & 11 & 59 & 18 \\
\hline 57. & 0 & 9 & 1 & 10 & 54 & 17 \\
\hline 58. & 0 & 8 & 2 & 09 & 49 & 15 \\
\hline 59. & 0 & 7 & 3 & 08 & 44 & 14 \\
\hline 60. & 0 & 6 & 4 & 07 & 39 & 12 \\
\hline 61. & 0 & 5 & 5 & 06 & 35 & 10 \\
\hline 62. & 0 & 4 & 6 & 05 & 30 & 09 \\
\hline 63. & 0 & 3 & 7 & 04 & 22 & 07 \\
\hline 64. & 0 & 2 & 8 & 03 & 20 & 06 \\
\hline 65. & 0 & 1 & 9 & 02 & 15 & 05 \\
\hline 66. & 0 & 0 & 10 & 01 & 10 & 03 \\
\hline
\end{tabular}


Table 2. Measurements of test arena.

\begin{tabular}{lccc}
\hline & Incubation zone & Transitional zone & Free zone \\
\hline Diameter $(\mathrm{cm})$ & 1.50 & 3.50 & 8.50 \\
Area $(\mathrm{sq} \mathrm{cm})$ & 1.77 & 9.62 & 56.74 \\
Weighted factor & 32.10 & 5.9 & 1.0 \\
\hline
\end{tabular}

Responses of S. glaseri towards different insects: Responses of nematodes towards attractants emitted by different insects were tested using the Petri-dish scoring system as described above. The two live and intact individuals of the last instar larvae of G. mellonella and the same number of the 3rd instar larvae of S. litura, B. germanica, L. migratoria were tested. The number of nematodes in each zone was recorded $6 \mathrm{hr}$ after the inoculation of nematodes.

Responses of $\mathrm{S}$. glaseri towards insect homogenate: Petri-dish scoring system for this experiment was used with the conditions as described above, excepting the time of observation and source of attraction. Instead of intact and live insects, homogenate (body fluids) of $G$. mellonella larvae was tested at five concentrations viz., 20, 40,60, 80 and 100\%. To prepare the stock homogenate (100\%) 10 last instar larvae of G. mellonella were homogenized in $10 \mathrm{ml}$ of distilled water, filtered, and stored at $4^{\circ} \mathrm{C}$ until it was used. Just prior to the experiment, the stock homogenate was diluted to the above concentrations and $1 \mathrm{ml}$ of each concentration was introduced in the straw pipe in the middle of the incubation zone. The distribution of nematodes was recorded $6 \mathrm{hr}$ after the incubation. The experiment was conducted with 20 replicates for each concentration. Control was run with distilled water.

Preference test chambers: Test chambers for determining preferential behaviour of nematodes were consisted of five transparent plastic Petri-dishes, each measuring $5.5 \mathrm{~cm}$ in diam. It was consisted of an inoculation chamber, four canals, and four test chambers. To make such chambers $8 \mathrm{~cm}$ long glass tube $(0.5 \mathrm{~cm}-\mathrm{d})$ was cut into four pieces, each of $2 \mathrm{~cm}$ in length, and named as canal. Four holes, each $0.5 \mathrm{~cm}-\mathrm{d}$ were made on the wall of one of the five Petri-dishes at $3,6,9$, and $12^{\circ}$ clock positions. The holes were made in such a way that they should touch the bottom of the Petri-dish. This Petri-dish was referred to as the inoculation chamber. One canal was then attached from outside to each of the four holes with an adhesive. The Petri-dish glued to the four canals was then left for $24 \mathrm{hr}$ to let the canal fixed firmly. Similarly, one hole of the same diameter was made on the walls of each of the four Petri-dishes (test chambers). One Petridish was then attached to each canal connecting to the inoculation chamber. Thus, the assembly as shown in Fig. 2 was obtained and named as preference test chambers. This model was then used to determine the absolute and relative preferential indices of the nematodes for different insects.

Absolute preferential indices of S. glaseri: The absolute preferential index was defined as the attraction response of nematodes that occurred towards the single insect. It was determined in relation to the total number of nematodes inoculated. The absolute preferential indices of $S$. glaseri for the insect emitted attractants were obtained using preferential test chamber as described above. A $4 \mathrm{~mm}$ thick layer of $1 \%$ water agar was made in the inoculation and one of the test chambers " $\mathrm{A}$ " including the canal connecting it to the inoculation chamber. The canal connecting the other three test chambers " $\mathrm{B}$ ", " $\mathrm{C}$ ", and "D" were sealed with filter paper. Fifteen last instar larvae of $G$. mellonella and the same number of the 3rd instar larvae of S. litura, B. 


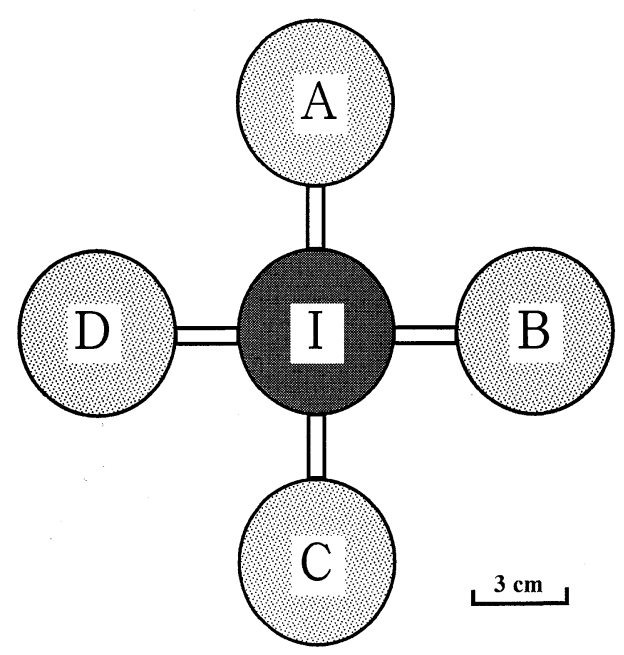

Fig. 2. Preference test chambers designed to test preference of Steinernema glaseri. A, B, C, and D: test chambers; I: inoculation chamber.

germanica, and L. migratoria were tested separately as the host by releasing them in the test chambers "A", one at a time. Both the inoculation and test chambers were then closed by the lids to prevent the escape of insects. The whole assembly was then left for $12 \mathrm{hr}$ at $28 \pm 1^{\circ} \mathrm{C}$ to allow the insects to emit attractants and develop minimum perceptible attraction gradient in the test chamber. After removing the insects from the test chambers 50 nematodes were released in the inoculation chamber. The distribution of nematodes in the test chamber and canal was recorded after $6 \mathrm{hr}$ and the absolute preferential index of nematodes for each species of the insect was obtained as follows. The nematodes if present in the canal, were counted along with the nematodes that were present in its corresponding test chamber. The control experiments were run without insects.

Absolute preferential index $(\%)=\frac{\text { Number of nematodes attracted by the insect }}{\text { Total number of nematodes inoculated }} \times 100$

Relative preferential index of S. glaseri: Relative preferential index was defined as the preferential response of nematodes that occurred for an insect in presence of others. It was determined in relation to other species of insects. The relative preferential indices of $S$. glaseri for the insect emitted attractants were obtained using preferential test chamber as described above. The thickness and concentration of agar layer and the temperature remained the same. In this experiment all the four insects were tested together and G. mellonella, S. litura, B. germanica, and L. migratoria were released in the test chambers A, B, C, and D, respectively. All chambers were then closed by the lids to prevent the escape of the insects. The whole assembly containing four different insects in four test chambers was then left for $12 \mathrm{hr}$ at $28 \pm 1^{\circ} \mathrm{C}$ to allow the insects to emit attractants and develop minimum perceptible attraction gradient in the test chambers. After incubation, 50 nematodes were released in the inoculation chamber. The distribution of nematodes in each observation chamber and canal was recorded after $6 \mathrm{hr}$ and relative preferential indices of nematodes for each species of insect were obtained as follows. The nematodes, if present in the canal were counted along with the nematodes that were present in 
its corresponding test chamber.

Relative preferential index $(\%)=\frac{\text { Number of nematodes attracted by the insect }}{\text { Total number of nematodes attracted by all the insects }} \times 100$ Nematodes attracted $=$ number of nematodes in the test chamber and its canal.

While determining relative preferential index for the four insects, the nematodes present in the inoculation chamber were not considered.

Statistical analysis: The overall differences among the means were tested using one-and-one way analysis of variance (ANOVA) and t-test. ScHEFFE test was used to test the differences in the preferential attraction responses of nematodes at $\mathrm{p}<0.05$. If necessary the data was transformed before analysis to equalize variances among treatments. When standard transformations failed to correct significant departures from assumptions of normality or equal variances, the MANN-WHITNEY rank sum test and ANOVA tests on ranks were used. The results in figures are reported as mean \pm standard deviation.

\section{RESULTS}

Responses of S. glaseri towards insect emitted attractants: Attraction response of S. glaseri towards insect emitted attractants increased significantly as the duration of observation increased from 1 to $6 \mathrm{hr}(\mathrm{r}=0.94 ; \mathrm{PEr}=0.003 ; \mathrm{p}<0.05) \quad$ (Fig. $3 \mathrm{~A})$. There was, however, no attraction at 1 and $2 \mathrm{hr}(\mathrm{p}>0.05)$. Maximum attraction was recorded at $6 \mathrm{hr}(\mathrm{p}<0.05)$. The distribution of nematodes corresponded to ranks $2(n=2), 3(n=4), 4(n=3), 5(n=5), 6(n=2)$, $15(n=1), 17(n=1), 18(n=1)$, and $24(n=1)$ with an average score of 34 after $1 \mathrm{hr}$ in the presence of host. Where " $n$ " is the number of times the distribution of nematodes corresponded to the same rank. The $1 \mathrm{hr}$ score corresponded to the mean attraction response (10.2\%) that is shown in Fig. 3A. At the end of 6 th $\mathrm{hr}$ the distribution of nematodes in the presence of insect corresponded to the higher ranks of $48(n=3), 49(n=3), 50(n=1), 54(n=2), 55(n=2), 58(n=1), 59(n=4), 61$ $(n=2), 62(n=1)$, and $64(n=1)$ with an average score of 218 . The 6 th hr score corresponded to higher mean attraction response of nematodes $(67.6 \%)$ that is represented in Fig. $3 \mathrm{~A}(\mathrm{p}<0.05)$.

Responses of S. glaseri towards different insects: The positive response of S. glaseri towards the attractants emitted by $G$. mellonella was the maximum $(\mathrm{p}<0.05)$. It was the least when $B$. germanica was tested $(\mathrm{p}<0.05)$ (Fig. $3 \mathrm{~B})$. The responses of nematodes were moderate towards the other two insect species. Between L. migratoria and $S$. litura the attraction response of $S$. glaseri was identical $(\mathrm{p}>0.05)$ but it was less than G. mellonella and more than B. germanica $(\mathrm{p}<$ 0.05). The distribution of nematodes corresponded to the ranks $35(n=1), 49(n=2), 50 \quad(n=2)$, $53(n=3), 54(n=4), 55(n=1), 56(n=1), 58(n=2), 59(n=2), 61(n=1)$, and $64(n=1)$ with an average score of 211 in the presence of $G$. mellonella, whereas, it corresponded to the ranks 35 $(n=1), 37(n=1), 39(n=1), 43(n=1), 44(n=1), 48(n=1), 49(n=3), 50(n=1), 51(n=2), 52$ $(n=2), 53(n=1), 54(n=1)$, and $55(n=3)$ with an average score of 178 when S. glaseri was tested with L. migratoria. In the presence of S. litura the distribution of S. glaseri corresponded to the ranks $35(n=2), 36(n=2), 37(n=1), 41(n=1), 42(n=3), 43(n=1), 48(n=1), 49(n=5), 50(n=$ 1), $53(n=1)$ and $54(n=2)$ with an average score of 163 and that with $B$. germanica it corresponded to ranks $18(n=1), 25(n=1), 27(n=2), 33(n=1), 34(n=2), 35(n=1), 36(n=2), 40(n=2)$, $41(n=1), 42(n=2), 43(n=1), 47(n=1), 48(n=1), 49(n=1)$, and $52(n=1)$ with an average 

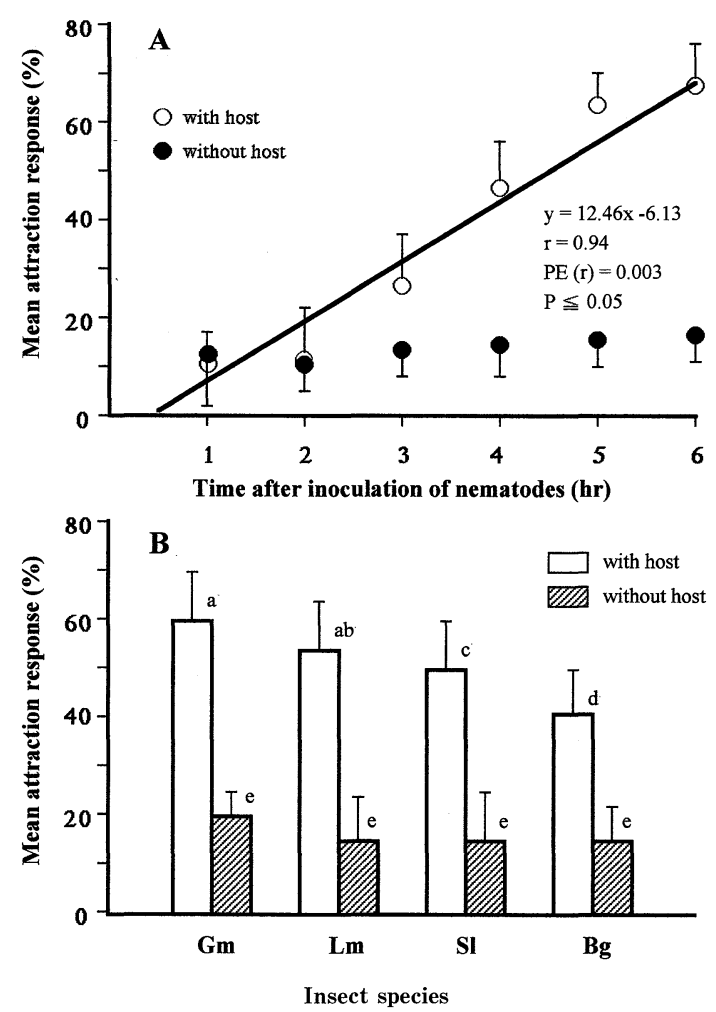

Fig. 3. A: Mean attraction response of Steinernema glaseri towards Galleria mellonella.

B: Mean attraction responses of Steinernema glaseri towards different insects: Gm, Galleria mellonella; Lm, Locust migratoria; Sl, Spodoptera litura; Bg, Blatella germanica. Bars show standard deviations. The letters $\mathrm{a}, \mathrm{b}, \mathrm{c}$, and $\mathrm{d}$ show significance at $\mathrm{p} \leqslant 0.05$ based on SCHEFFE test. All differences are significant except "ab"

score of 134. Where " $n$ " is the number of times the distribution of nematodes corresponded to the same rank. The average scores for G. mellonella (211), L. migratoria (178), S. litura (163), and B. germanica (134) corresponded to mean attraction response of $65.2 \%, 55.0 \%, 50.7 \%$, and $41.7 \%$, respectively, as shown in Fig. $3 \mathrm{~B}$.

Responses of $\mathrm{S}$. glaseri towards insect homogenate: Homogenate concentrations containing body fluids of $G$. mellonella elicited differential responses of $S$. glaseri. The attraction of $S$. glaseri increased with the increase in the concentration of the homogenate $(r=0.97 ; \mathrm{PEr}=0.001$ : $\mathrm{p}<0.05$ ) (Fig. 4). It was recorded maximum when the concentration was $100 \%$ and the least when $20 \%$ homogenate concentration was tested $(\mathrm{p}<0.05)$.

Absolute preferential indices of S. glaseri: The absolute preferential index of S. glaseri for the insect emitted attractants was maximum for $G$. mellonella whereas it was the least in case of B. germanica $(\mathrm{p}<0.05)$ (Fig. 5A). The absolute preferential indices for the other two insects were moderate that was less than G. mellonella but more than B. germanica. Between $L$. migratoria and $S$. litura the nematodes exhibited identical absolute preferential index $(\mathrm{p}>0.05)$. 


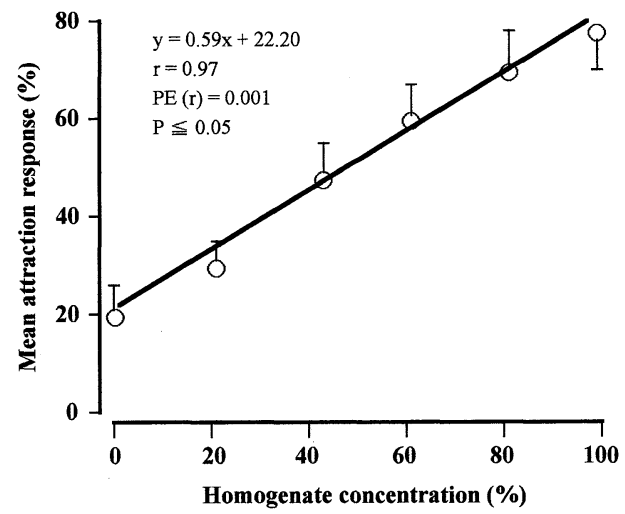

Fig. 4. Responses of Steinernema glaseri towards homogenate concentrations of Galleria mellonella larvae. Bars show standard deviations. The letters a, b, c, and d show significance at $\mathrm{p} \leqslant 0.05$ based on ScheFFE test. All differences are significant except "bc".
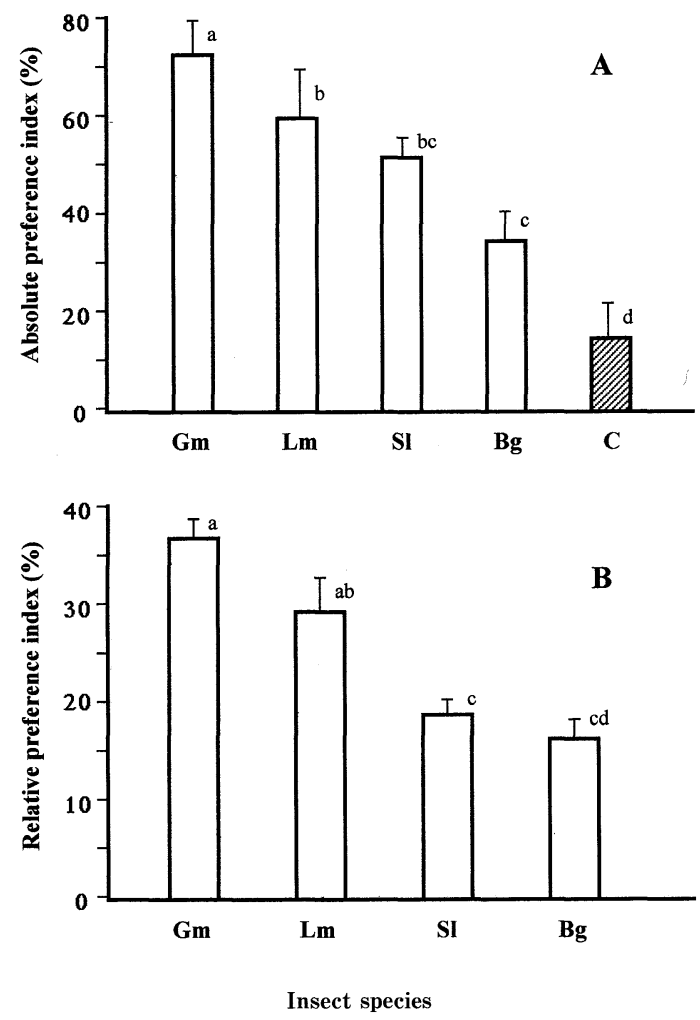

Fig. 5. Host preference behaviour of Steinernema glaseri. $\mathrm{A}=$ response towards single insect (absolute preference indices). $\mathrm{B}=$ responses towards different hosts tested together (relative preference indices). Gm, Galleria mellonella; Lm, Locust migratoria; S1, Spodoptera litura; $\mathrm{Bg}$, Blatella germanica; $\mathrm{C}=\mathrm{control}$ (without insect). Bars show standard deviations. The letters a, b, c, and $\mathrm{d}$ show significance $\mathrm{p} \leqslant 0.05$ based on SCHEFFE test at 0.05. All differences are significant except "ab" and "cd". 
Relative preferential indices of S. glaseri: The relative preferential index of S. glaseri was also recorded highest for $G$. mellonella and the least when B. germanica was tested $(\mathrm{p}<0.05)$ (Fig. $5 \mathrm{~B})$. There was no significant difference in the relative preferential indices of S.glaseri between G. mellonella and L. migratoria and S. litura and B. germanica $(\mathrm{p}>0.05)$.

\section{DISCUSSION}

The proposed model, Petri-dish scoring system is based on the probability of nematode's distribution in the three zones of a Petri-dish. Thus, according to the law of probability during random distribution, the number of nematodes present in each zone should be proportional to the area of the respective zones. Therefore, during such a movement more number of nematodes should be present in the free zone, lesser in the transitional and practically none or the least in the incubation zone. As a result of the stimulation from the host kairomones the distribution pattern of nematodes may change and more nematodes migrated to transitional and then incubation zones. So, depending upon the number of nematodes reaching to the incubation zone, the area of the three zones and the distribution patterns of nematodes, a system for giving weightage, ranking and scoring nematode combinations is formulated. Quantitative analysis of attraction responses of nematodes and their numerical values may then be obtained by considering the above mentioned attributes. Maximum response that the nematode can show under proposed method is $100 \%$ i.e., when all the 10 nematodes were present in the incubation zone. Such a distribution was therefore given the highest ranking "66" and maximum score " 321 ". Therefore, this score " 321 " was considered as the standard response of the nematode for making quantitative analysis and obtaining numerical values for nematode's response to insect attractants. The reason why a circular test arena was selected is because of its advantage over the narrow strip. Many nematodes leave strips and become trapped affecting the outcome of the experiment. The circular and wider area like the proposed one allows attraction gradients to disperse in all directions uniformly, and nematodes to move unrestrictedly. The proposed model was then tested successfully with S. glaseri using G. mellonella, S. litura, B. germanica, and L. migratoria. During present study the distribution of nematodes in the three zones in the presence or absence of the insect was a determinant factor. The differential ranking of nematodes distribution in the three zones of the Petri-dish, the average score and the mean attraction responses of S. glaseri in the presence or absence of the hosts and at the end of 1 and $6 \mathrm{hr}$ in the presence of the insects suggest its responsiveness towards insect emitted attractants. The distribution of nematodes corresponding to higher ranks, scores and mean attraction response may be considered as the criteria for differentiating nematodès responsiveness to attractants from its random locomotory behaviour. The mean attraction responses of nematodes depended positively upon the duration of observation besides the homogenate concentrations of the insect larvae. In the former event it may be the minimum perceptible attraction gradient and minimum response threshold of predators that appeared to have made the differences as the two characteristics vary inter- and intra-specifically (9). Formation of minimum perceptible attraction gradient in a medium around nematodes is an important attribute that may influence nematode's sensory responses. With our studies on the concentrations of insect homogenate and otherwise it may be concluded that an optimum concentration of the attraction gradients (20\% in the present study) is necessary to develop minimum perceptible attraction gradient and an optimum time (2-3 hr in the present study) is 
required by the nematodes to perceive it at their minimum response threshold. Various concentrations of the insect homogenate were tested to study attraction responses of nematodes in comparison to the intact hosts.

Our studies on the preferential behaviour of S. glaseri yielded significant results with preferential test chambers. This experimental model determined absolute and relative preferential indices of nematodes for different insects under conditions where chemical gradients from different insects interact with each other. The stability of the attractants that were diffused in the medium by different insect may be determined by the attractants with the high rate of emission and diffusion but low rate of degradation. Only such attractants may survive and hold the competition to attract the responding nematodes. Our experiments on the preferential behaviour with this model and the Petri-dish scoring system revealed identical preferential patterns of S. glaseri for various species of insects. Identical responses of S. glaseri in two different experimental bioassays suggest their preferential behaviour. G. mellonella elicited maximum response of nematodes with high absolute and relative preferential indices of nematodes. S. glaseri attained lowest values for the absolute and relative preferential indices when $B$. germanica larvae were tested. This differential response of nematodes towards different species of insect may be attributed to the variations in the biochemical composition, concentration, quality and quantity of insect secretions (4) that are still to be investigated. One of the factors contributing low absolute and relative preferential indices for the cockroach may be its ammonotellic nature. The avoidance behaviour of entomopathogenic nematodes has been reported in the presence of cockroaches due to the excretion of ammonia (1).

\section{ACKNOWLEDGEMENTS}

The first author is grateful to the Japanese Society for Promotion of Science for extending invitation as Visiting Fellow of the Society to carry out research in the Department of Applied Biological Sciences, Saga University, Saga, Japan. We are grateful to Mr. Hiroshi TANABE, SDS Biotech K. K., Tsukuba Technology Center, Ibaraki, Japan for providing S. glaseri for the present study.

\section{LITERATURE CITED}

1) Bell, W. J. \& AdiYodi, K. G. (1981) The American Cockroaches. Chapman and Hall, London, 527 pp.

2) Bilgrami, A. L. (1995a) Numerical analysis of the relationship between the predation by Mesodorylaimus bastiani (Nematoda: Dorylaimida) and different prey trophic categories. Nematol. medit. 23, 81-88.

3 ) Bilgrami, A. L. (1995b) Effect of age of roots and starvation on the attraction of Tylenchorhynchus mashoodi towards cabbage roots. Ann. P1. Prot. Sci. 3, 127-131.

4 ) Bilgrami, A. L. (1996) Attraction and feeding behaviour of Tylenchorhynchus mashhoodi. Ann. Plt. Pro. Sc. 2, 33-38.

5 ) Fan, X. \& Hominick, W. M. (1991) Efficiency of the Gallaria (wax moth) baiting technique for recovering infective stages of entomopathogenic rhabditids (Steinernematidae and Heterorhabditidae) from sand and soil. Rev. Nematol. 14, 381-387.

6 ) Grewal, P. S., Gaugler, R. \& Lewis, E. E. (1993) Host recognition behaviour by entomopathogenic nematodes during contact with insect gut contents. J. Parasitol. 79, 495-503.

7 ) Khlibsuwan, W., Ishibashi, N. \& Kondo, E. (1992) Effects of enzymes, chemicals and temperature 
on Steinernema carpocapsae attraction to host plasma. J. Nematol. 24, 482-488.

8 ) Molye, P. L. \& Kaya, H. K. (1981) Dispersal and infectivity of the entomopathogenic nematode, Neoaplectana carpocapsae WeIser (Rhabditida: Steinernematidae) in sand. J. Nematol. 13, 295-300.

9 ) Pervez, R. \& Bilgrami, A. L. (2000) Some factors influencing chemo attraction behaviour of dorylaim predators, Laimydorus baldus and Discolaimus major towards prey kairomones. Int. J. Nematol. 10, 41-48.

10) Young, I. M., Griffths, B. G. \& Robertson, W. M. (1996) Continuous foraging by bacterial feeding nematodes. Nematologica 42, 378-382.

Accepted for publication: September 7, 2000.

\section{和文摘要}

\section{宿主昆虫への Steinernema glaseri の誘引および 選択行動の試験モデル}

\section{A. L. BILGRAMI・近藤 栄造・吉賀 豊司}

ペトリ皿を用いた行動解析試験結果に基づき、Steinernema glaseri 感染態幼虫の誘引行動と選択性 のモデルを提唱した。前者では、宿主昆虫から発散する誘引物質の有無に基づく線虫の分布確率をス コアー化し、宿主に到達した線虫数に重みづけを行い、その結果に基づいて、線虫の誘引行動を数量 的に解析した。後者では、4 種昆虫(ハチミツガ、ハスモンヨトウ、チャバネゴキブリ、トノサマバッ 夕）への線虫の選択性を試験した。誘引源への線虫の誘引率は時間とともに高くなり、線虫接種 6 時 間後には最高 $(67.6 \%)$ に達した。ハチミツガ幼虫の摩砕液への誘引率は、摩砕液の濃度に依存した。 誘引試験ならびに 4 種昆虫を用いた選択試験の結果、S. glaseri 感染態幼虫の選好性は、ハチミツガ幼 虫に対して最も強かった。 